\title{
ISOLATED INFUNDIBULAR PULMONARY STENOSIS IN ADULT: A CASE REPORT
}

RAHMAN MM ${ }^{1}$, SUNNY MSA ${ }^{2}$, HASAN MK ${ }^{3}$, ADHIKARY AB ${ }^{4}$,

\begin{abstract}
:
Isolated infundibular pulmonary stenosis (IIPS) in adult is an uncommon cardiac abnormality. Infundibular pulmonary stenosis leading to right ventricular hypertrophy is a big problem. Early excision of hypertrophied muscular band can overcome this problem. In our case report we have done excision of pulmonary infundibular muscle band of a late case of isolated pulmonary infundibular stenosis. And our patient showed a good response after excision of infundibular muscle band.
\end{abstract}

Key words: Isolated Infundibular Pulmonary Stenosis, Excision of infundibular muscle band.

J Dhaka Med Coll. 2014; 23(1) : 140-142.

\section{Introduction:}

Obstruction to the outflow of blood from the right ventricle may occur as a result of congenital stenosis of pulmonary valve, of the infundibulam, or of the supravalvular area. These all result in a fixed constriction of the lumen of the involved region. Recently, considerable interest has been focused upon a more dynamic type of infundibular obstruction that occurs a number of patients without valvular pulmonary obstruction and an intact ventricular septum. ${ }^{1}$ The hemodynamic consequence of the obstruction is elevated pressure within the RV cavity. Subsequent elevation of end-diastolic pressure and decreased compliance of the RV, consequent to the hypertrophy, lead to elevated right atrial (RA) pressure and dilatation of that chamber. Deformity and malfunctioning of the LV occur in proportion to RV hypertension. The resultant chronic pressure overload can lead to RV dilation, biventricular dysfunction, heart failure symptoms, arrhythmias, and sudden death. Excision of pulmonary infundibular muscle band can lead to improvement in functional class and a substantial decrease or normalization of RV pressure. Other potential benefit is improvement in exercise capacity. Associated defects, especially ventricular septal defect. ${ }^{2}$

\section{Case report:}

A 38 year old female garments worker admitted on 08.10.2013 under orange unit of Cardiac Surgery, BSMMU with the complaints of chest heaviness and shortness of breath for 1year. On examination the patient was short stout with average body built, there was systolic thrill over the pulmonary area. First heart sound normal, Second heart sound soft, there was systolic murmur best heard in pulmonary area. Lungs clear with no added sound. ECG showed heart rate $85 / \mathrm{min}$, regular with right ventricular hypertrophy with strain pattern. Chest x-ray shows cardiomegaly. Colour doppler echocardiogram showing (Fig-1) severe infundibular pulmonary stenosis (RVOT to PA PPG: $163 \mathrm{mmHg}$ ), marked concentric RV hypertrophy with good RV systolic function and mild to moderate tricuspid regurgitation. Cardiac catheterization (Fig-2) data showing RV systolic pressure $160 \mathrm{~mm}$ of $\mathrm{Hg}$ and diastolic pressure $10 \mathrm{~mm}$ of $\mathrm{Hg}$ with good PA anatomy. Pressure gradient was found from RV to PA level (160 $-20=140 \mathrm{~mm}$ of $\mathrm{Hg}$ ).

The patient was operated on 20.10.2013. Under general anaesthesia, with all aseptic precautions median sternotomy done. After thymus dissection pericardiotomy done. Cardiopulmonary bypass was established with

1. Dr. Md.Mostafizur Rahman, Associate Professor, Department of Cardiac Surgery, Bangabandhu Sheikh Mujib Medical University, Shahbagh, Dhaka.

2. Dr. Mohammad Samir Azam Sunny, Medical Officer, Department of Cardiac Surgery, Bangabandhu Sheikh Mujib Medical University (BSMMU), Dhaka.

3. Prof. Md. Kamrul Hasan, Professor, Department of Cardiac Surgery, NICVD, Dhaka

4. Prof. Asit Baran Adhikary, Professor, Department of Cardiac Surgery, Bangabandhu Sheikh Mujib Medical University (BSMMU), Dhaka.

Correspondence: Dr. Md. Mostafizur Rahman, Associate Professor, Department of Cardiac Surgery, Bangabandhu Sheikh Mujib Medical University (BSMMU), Dhaka. Cell Phone: +8801713032504. 
bicaval cannulation with aortic cannulation. Heart was arrested by giving cross clamp and antegrade cardioplegia under mild hypothermia $\left(32^{\circ} \mathrm{C}\right)$. Dissection of pulmonary artery done along with ligation of fibrous band on aortopulmonary groove. RAtomy and PAtomy done. Pulmonary valve was found normal with gross hypertrophy of infundibular muscle band (Fig-3). Total excision of infundibular muscle band done. Hager's dilator (20 $\mathrm{mm}$ ) easily passed through RVOT. PA closed by continuous stitch. Then RA closed. Patient weaned from CPB without any difficulty. RV pressure measured by introducing a catheter through PA. Normal RV pressure $(20 / 5 \mathrm{~mm}$ of $\mathrm{Hg}$ ) recorded. X-clamp time-30 min, Total bypass time-60 min. After achieving haemostasis chest was closed leaving two right ventricular epicardial pacing wire and two mediastinal chest drain (retrocardiac 32 Fr and right pleural $32 \mathrm{Fr}$ ) tubes attached with underwater seal drain bags. The patient was shifted to the intensive care unit with minimum inotropic support. Patient was extubated on the same day, shifted to general ward on the $3^{\text {rd }}$ post operative day and discharged home on the $10^{\text {th }}$ postoperative day. The patient remains asymptomatic on the subsequent follow up. The patient is on minimum medication and leading a normal life.

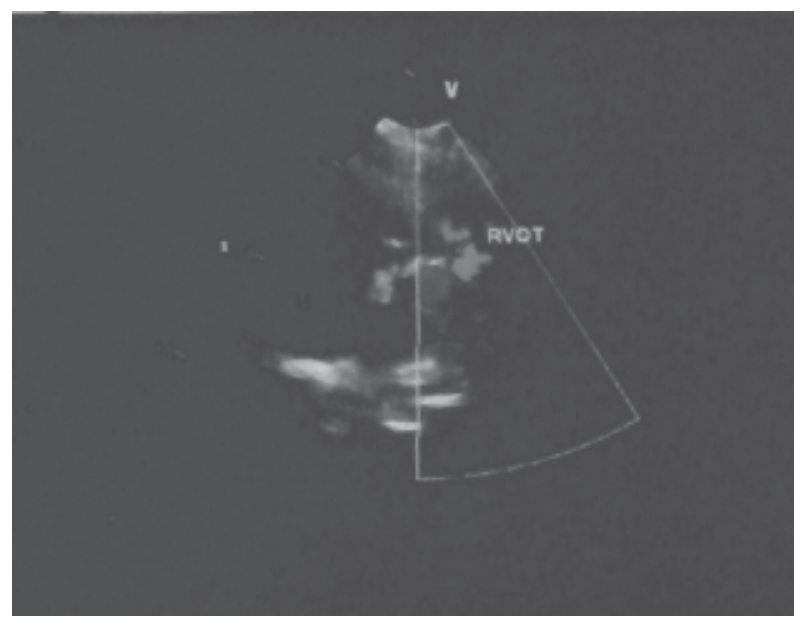

Fig.-1: Echocardiograph showing hypertrophied RV causing RVOT obstruction.

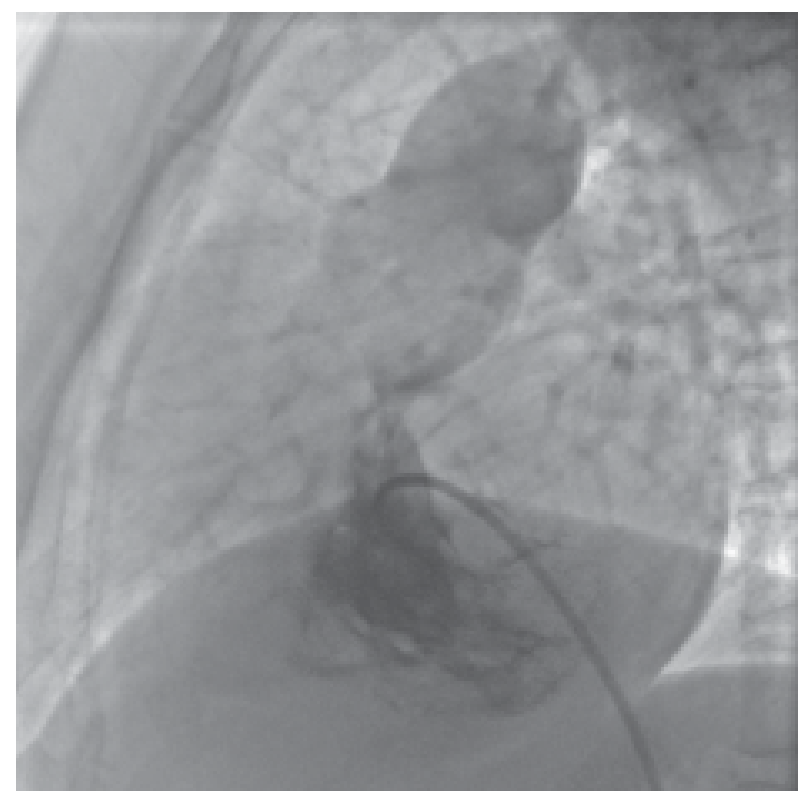

Fig.-2: Right heart catheterization showing infundibular muscle band.

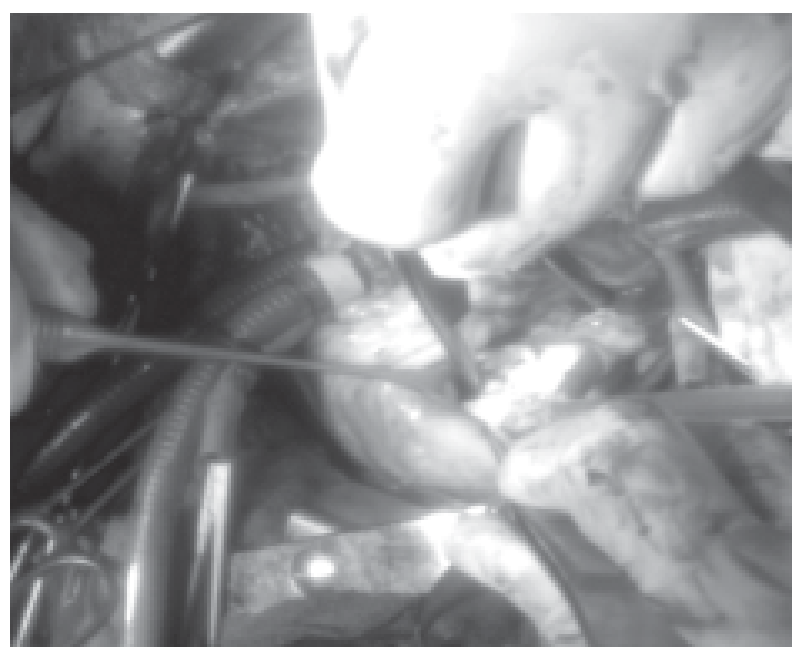

Fig.-3: Infundibular muscle band in RV.

\section{Discussion:}

Isolated infundibular pulmonary stenosis (IIPS) is an uncommon cardiac abnormality, with a reported incidence of $0.4 \%$ of patients with congenital heart disease. ${ }^{3}$ The most successful cases are those in which the obstruction is muscular and only involve a short segment of the outflow tract. ${ }^{4}$ Other conditions causing RVOT obstruction are protrusion of right sinus of valsalva into the RVOT, aneurysm of membranous ventricular septum, and intra and extracardiac mass lesions in the RVOT such as sarcoma. ${ }^{3}$ 
Infundibular pulmonary stenosis is present from birth, although most patients are asymptomatic. The severity of stenosis can progress with age. Dyspnea and fatigue are the most common symptoms. Exertion may provoke syncope or even death. Precordial pain is common, and epigastric pain is often present. ${ }^{2}$ In this case, the patient had been symptomatic with chest heaviness and shortness of breath for last 1 year and was first diagnosed in her late 38 years of age because no shunt was present.

Indications for surgical intervention include presence of such symptoms (shortness of breath, cyanosis and chest pain) and severe stenosis with gradients exceeding $100 \mathrm{~mm} \mathrm{Hg}$, even if the patient is asymptomatic. ${ }^{2}$ Our patient had RV to PA pressure gradient $140 \mathrm{~mm}$ of $\mathrm{Hg}$ which support this data. Surgical correction of isolated infundibular pulmonary stenosis over 35 years old had been rarely reported. In addition, it was the first case report of IIPS which was surgically corrected successfully in BSMMU, Dhaka.

\section{References:}

1. Little JB, Lavender JP, Desanctis RW. The Narrow Infundibulam in Pulmonary valvular Stenosis: Its prospective diagnosis by Angiocardiography. Circulation 1963; 28: 186-9.

2. Venugopalan P. Infundibular Pulmonary Stenosis.http: / / emedicine.medscape.com / article/900407 (accessed on 25 June, 2012).

3. Kurup V, Perrino A, Barash P, Hashim SW. Infundibular Pulmonary Stenosis. Echo Rounds 2007; 104: 507-8.

4. Temesvary A. A method of treating Infundibular Pulmonary Stenosis. Thorax 1958; 13: 165-8. 